\title{
Editorial
}

\section{Aspectos discursivos na mídia e no ensino em diferentes temas}

\author{
Maria das Graças Soares Rodrigues* \\ gracasrodrigues@gmail.com \\ https://orcid.org/0000-0002-8295-358X
}

\section{Maria Eduarda Giering ${ }^{* * *}$}

eduardag@unisinos.br

https://orcid.org/0000-0001-8098-4238

\author{
Zilda Gaspar Oliveira de Aquino ** \\ ziaquino@usp.br \\ https://orcid.org/0000-0003-0432-7046
}

\author{
Maria Inês Batista Campos ${ }^{* \star * *}$ (i) \\ maricamp@usp.br \\ https://orcid.org/0000-0003-0004-9923
}

E o que dizer das textualidades orais (monogeradas e poligeradas) e das textualidades digitais? A essa diversidade, junta-se outra dificuldade: o conceito de texto é o objeto legítimo de disciplinas tão diferentes como a retórica, a hermenêutica, a estilística, a filologia, a textologia, a poética, a semiótica, as ciências da informação e da comunicação, a genética, a lógica e a filosofia. Além disso, já no final da década de 1920, Vološinov (2010) não questionava a própria possibilidade do estabelecimento de um conceito linguístico de texto?

Jean-Michel ADAM

Em cada momento concreto de sua formação, a língua é estratificada em camadas não só de dialetos no exato sentido do termo [...], mas também - o que é essencial para nós - em linguagens socioideológicas: linguagens de grupos sociais, profissionais, de gêneros, linguagens de gerações, etc. [...] A estratificação e o heterodiscurso se ampliam e se aprofundam enquanto a língua está viva e em desenvolvimento [...].

* Doutora e pesquisadora da Universidade Federal do Rio Grande do Norte, Natal, Brasil.

** Doutora e pesquisadora da Universidade de São Paulo, Brasil.

*** Doutora e pesquisadora da Universidade do Vale do Sinos, Unisinos, Porto Alegre, Rio Grande do Sul, Brasil.

${ }^{* * * *}$ Doutora e pesquisadora da Universidade de São Paulo, Brasil

\section{LINHA DÁGUA}


Neste número 34/1 de Linha d'Água, o objetivo é apresentar artigos voltados à pesquisa no âmbito dos estudos da linguística enunciativo-discursiva, reunindo, assim, publicações em que se explorem o texto e o discurso em diferentes perspectivas teóricas e suas relações com o ensino. Os pesquisadores da área dos estudos do discurso propõem vários enfoques e corpus de análise discutindo dimensões linguístico-discursivas com o propósito de compreender as várias interações comunicacionais.

Alguns estudos seguem princípios metodológicos fundados da Teoria Semiolinguística de Discurso (TSD), modelo de análise concebido por Patrick Charaudeau, para quem "todo ato de linguagem, qualquer que seja sua dimensão, nasce, vive e toma sentido numa situação de comunicação" (CHARAUDEAU, 2006a, p. 1). A TSD propõe considerar as interações humanas numa perspectiva comunicacional, ou seja, como fatos de comunicação, os quais têm uma dupla dimensão: uma externa e outra interna à linguagem (CHARAUDEAU, 2004). Na dimensão externa, ou propriamente comunicacional, encontram-se os dados que, embora sejam exteriores ao discurso, desempenham papel de coerção sobre o linguageiro.

Para melhor compreender as relações entre essas duas dimensões, voltamo-nos para postulados charaudeanos acerca dos três níveis de análise linguística, cada um correspondendo a um tipo de competência (CHARAUDEAU, 2004), os quais se relacionam entre si, num verdadeiro vai-e-vem: o nível situacional, o discursivo e o semiolinguístico. O situacional é o lugar onde se encontram os dados externos, que impõem restrições aos demais níveis: tanto ao discursivo, em que se instauram as diferentes maneiras de dizer do enunciador, quanto ao nível semiolinguístico, lugar das escolhas verbais e icônicas que configuram os textos.

A "situação de comunicação" (CHARAUDEAU, 2016) determina, assim, o espaço da troca linguageira e suas condições de produção. É neste lugar que se situam as instruções que determinam as expectativas das interações entre interlocutores, as quais são provenientes, ao mesmo tempo, da identidade dos parceiros, ou seja, do lugar social que ocupam na troca; da temática envolvida; da finalidade da interação e das circunstâncias materiais nas quais ela se realiza. As perguntas que correspondem a esses componentes de uma situação de comunicação são respectivamente: Quem comunica o quê? Sobre o que se fala? Com que finalidade? Em que circunstância?

Os dados externos da situação de comunicação, ao serem percebidos, depreendidos e reconhecidos, atuam sobre os comportamentos linguageiros dos parceiros da troca, ou seja, sobre o "como dizer"; são as maneiras de falar, os papéis linguageiros que devem ou podem ser assumidos, as formas verbais e icônicas a serem empregadas. No entanto, como observa Charaudeau (2006b), essa sobredeterminação da situação de comunicação é parcial, pois o sujeito dispõe de uma margem de manobra que lhe permite realizar seu projeto de fala. $\mathrm{O}$ linguista esclarece:

contrato de comunicação e projeto de fala se completam, trazendo, um, seu quadro de restrições situacionais e discursivas, outro, desdobrando-se num espaço de estratégias, o que faz com que todo ato de linguagem seja um ato de liberdade, sem deixar de ser uma liberdade vigiada. (CHARAUDEAU, 2006b, p. 71) 
Outro aspecto importante a ser destacado nos postulados da TSD diz respeito às condições situacionais para a ocorrência de uma possível intercompreensão entre os sujeitos da troca de linguagem. Os indivíduos de uma comunidade social se apoiam em um quadro de referência comum, a fim de interagirem e alcançarem certa intercompreensão, que depende, em parte, das condições nas quais essa interação se realiza. Os elementos em jogo numa situação de comunicação são, na verdade, conforme Charaudeau (2006b), um conjunto de condições não enunciadas que estabelece algumas condições para a determinação do sentido. O linguista denomina de "contrato" (CHARAUDEAU, 2010, p. 14) esse quadro ao qual se reportam os indivíduos de uma comunidade social quando iniciam uma troca de linguagem. A situaçãocontrato de comunicação proporciona aos sujeitos produtor e interpretante instruções de construção/interpretação do sentido.

É o contrato de comunicação que permite que os atos de linguagem sejam reconhecidos como válidos numa determinada situação, ou seja, que correspondam a uma intencionalidade do locutor e possam ser interpretados pelo interlocutor. Para isso, é preciso que ambos os sujeitos possuam certo saber em comum, não somente em relação às ideias, mas também quanto às normas próprias de determinado campo e situação específica.

Para pensar sobre como se estrutura uma situação de comunicação, como ela impõe suas restrições e como ela se apresenta, enquanto lugar de construção do sentido, o autor propõe que se focalize, inicialmente, os "domínios de prática", lugares de produção das interações sociais organizadas em setores de atividade social que se definem por um conjunto de práticas. "Eles resultam de um jogo de regulação das relações de força que aí se apresentam e instauram um recorte do espaço social como lugar simbólico de uma atividade ordenada de atores sociais em torno de uma finalidade que implica regras de troca" (CHARAUDEAU, 2010, p.11). O midiático, o político, o religioso ou o científico são exemplos de domínios de prática, lugares onde diferentes disciplinas podem se encontrar fazendo circular seus conceitos.

Quando o domínio de prática social se organiza em domínio de troca comunicacional, temos, então, uma "situação global de comunicação", conforme Charaudeau (2010). Definemse, desse modo, instâncias de comunicação, papéis a serem desempenhados, tipos de relações entre eles, finalidade discursiva, temáticas próprias. O midiático é um exemplo de situação global de comunicação, que propõe papéis discursivos, uma finalidade - "fazer saber e comentar os acontecimentos do mundo" - e um domínio temático de "acontecimentos que se produzem no espaço público imediato", o que, segundo o autor, explicaria a conivência que pode se produzir entre o discurso político e o discurso de informação midiático.

Um segundo lugar de estruturação do domínio de prática é a "situação específica de comunicação", onde são determinadas as condições físicas da situação de linguagem, que são subordinadas aos termos da situação global. No caso da situação de comunicação midiática, é o momento de descrevemos a troca interacional de forma mais específica, identificando os sujeitos participantes, suas identidades sociais e papéis comunicacionais desempenhados. Da mesma forma procedemos com a finalidade da interação e com o domínio temático, os quais

\section{LINHA DÁGUA}


são, neste caso, particularizados em função das circunstâncias materiais nas quais se desenrolam efetivamente. Detalhando o domínio midiático tomado no exemplo, poderíamos ter situações específicas como boletins radiofônicos, manchetes de jornal, editoriais de imprensa, reportagens etc., vistos como subconjuntos do dispositivo conceptual de "informação midiática" (CHARAUDEAU, 2010). Nesse sentido, para o autor, os gêneros discursivos são, antes, gêneros situacionais.

Diante disso, é importante destacar a hipótese da TSD de que o sentido de um ato de linguagem não reside somente em sua manifestação verbal, nem somente em seu sentido explícito contido no enunciado produzido. Os enunciados, na verdade, só são interpretáveis considerando os condicionamentos partilhados pelos parceiros da troca linguageira, no espaço em que se define o "jogo de expectativas" da troca comunicativa. Segundo o autor, "o sujeito falante fabrica seu enunciado em função de certo "jogo de expectativas" ao distribuir nos atos de linguagem os sentidos explícitos e implícitos segundo as possibilidades inferenciais que atribui ao seu interlocutor" (CHARAUDEAU, 2010, p. 4).

Dentro de uma problemática de influência, princípio que leva os parceiros da comunicação a produzir discursos que visam a ter um certo impacto um sobre o outro (CHARAUDEAU, 2004), o linguista concebe a comunicação como uma encenação, realizada pelo sujeito do discurso, de "estratégias orientadas para o outro" (CHARAUDEAU, 1995). Essas estratégias se organizam conforme o efeito pretendido e o efeito produzido, de acordo com o modelo discursivo que contempla o duplo espaço externo e espaço interno à linguagem. Os efeitos pretendidos são aqueles que o sujeito comunicante busca produzir sobre um sujeito destinatário idealizado; os efeitos produzidos são aqueles que o sujeito interpretante reconhece efetivamente, construindo-os e reconstruindo-os a seu modo. Assim considerando, o autor (2019, p. 35) concebe o texto como "portador de um conjunto de efeitos possíveis, correspondentes tanto aos efeitos pretendidos da instância de comunicação quanto aos efeitos produzidos pela instância de interpretação".

O leitor conta também com a teoria de Jean-Michel Adam, fundador da Análise Textual dos Discursos (ATD). Nessa direção, a epígrafe de Adam (2019), na abertura desse editorial, sintetiza aspectos discutidos em alguns dos artigos que desenvolveram análises de dados digitais, escritos e orais. As análises consideram tanto a segmentação de zonas textuais mais extensas, como os efeitos de continuidade textual decorrentes das operações de ligação de unidades. ADAM (2020, p.2) nos aponta uma questão emergente: trabalhar “[...] as formas de textualidade em paralelo com a exploração dos gêneros de discurso, pois não há efeito de texto sem efeito de genericidade".

Igualmente se conta com a abordagem teórica de Alain Rabatel, cujos trabalhos focalizam o ponto de vista, a responsabilidade enunciativa, as posturas enunciativas entre outros dispositivos enunciativos. Para tratar da leitura literária e do ensino de língua portuguesa na formação do professor, o quadro teórico se constitui de autores tanto brasileiros Regina Zilberman, Clécio Bunzen, Roxane Rojo como estrangeiros Bernard Lahire, Bernard

\section{LINHA D'́GUA}


Schneuwly, Joaquim Dolz. A interrelação entre normas e análise conversacional foi analisada à luz das propostas de Catherine Kerbrat-Orecchioni, Dino Pretti, e a questão jurídica com abordagem de Mauro Cappelletti e Bryant Garth.

Ressalta-se a abordagem da escrita como processo, Charles Bazerman, Sueli Cristina Marquesi, Rosalice Pinto, entre outros. No que diz respeito às metodologias ativas, Jonathan Bergmann, Aaron Sams, Luciane Penteado Chaquime e Daniel Mill. Por fim, a reflexão acerca da interpretação de imagens em manuais de língua portuguesa do ensino médio, destacam-se contribuições advindas da multimodalidade, na perspectiva de Gunther Kress, de Ângela Dionísio; assim como o letramento visual, de acordo com Suzanne Stokes.

Este número conta também com artigos de autores que integraram o Projeto "Língua Portuguesa no ensino básico e superior: dos gêneros textuais/discursivos do livro didático, acadêmicos, jurídicos e políticos às estratégias de textualidade da oralidade e da escrita" reuniu três Universidades brasileiras - Universidade de São Paulo, Universidade Federal do Rio Grande do Norte e Universidade do Vale do Rio dos Sinos (USP/UFRN/UNISINOS) - e constituiu uma oportunidade extremamente produtiva de trocas acadêmicas para os cursos de Letras das instituições mencionadas. A vigência deu-se de outubro de 2014 a setembro de 2020 e, durante todo o período, contou com financiamento da CAPES-PROCAD.

O PROCAD é um Programa Nacional de Cooperação Acadêmica, instituído pela CAPES (Coordenação de Aperfeiçoamento de Pessoal de Nível Superior), com o objetivo de propiciar a formação de recursos humanos, por meio de projetos conjuntos entre Universidades brasileiras. Prevê, ainda, que a intensificação de pesquisas científicas, por meio de intercâmbio interinstitucional, promova a elevação da qualidade do ensino, tanto da graduação, quanto da pós-graduação.

Os projetos submetidos a esse Programa (PROCAD) devem observar um funcionamento que leve em conta o planejamento de missões de estudo, docência, pesquisa e estágio pós-doutoral que permita alcançar o objetivo central mencionado, além de também estar previsto que essas missões contem com custeio total da CAPES. Nessa direção, destaca-se que Projetos dessa ordem preveem a implantação de uma rede de cooperação acadêmica entre programas consolidados, com a finalidade maior de propiciar o fortalecimento e o avanço, não só das pesquisas, mas também da produção científica conjunta entre as Universidades participantes.

Por seu turno, o projeto específico que desenvolvemos teve por proposta fomentar a realização de projetos de ensino e de pesquisa, com a finalidade de focalizar a língua portuguesa na educação básica e superior, de modo a integrar uma rede de professores pesquisadores, doutorandos, mestrandos e alunos de iniciação científica das três equipes envolvidas (USP / UFRN / UNISINOS), apoiando a realização de missões, estágios sanduíches, pós-doutorados e a participação em eventos nacionais e internacionais. Esse intercâmbio entre professores e alunos teve por fio condutor permitir que se conhecessem e auxiliassem mutuamente no

\section{LINHA D'́GUA}


desenvolvimento de ações educacionais, a fim de se alcançar a melhoria dos resultados desde o ensino básico até o superior no país, sem perder de vista que as instituições envolvidas localizam-se em regiões diversificadas do país e que, portanto, é preciso valorizar as especificidades culturais que se apresentam, mas tendo em vista a redução de qualquer assimetria.

Além de se pensar/repensar o ensino de língua portuguesa, os gêneros textuais/discursivos constituíram o foco desse ensino, observados em esferas diversificadas e em sua circulação no livro didático, nos meios acadêmicos, jurídicos e políticos. As modalidades falada e escrita receberam atenção dos pesquisadores docentes e discentes. É perceptível a densidade e a complexidade de uma proposta dessa ordem que exigiu dedicação e envolvimento intenso de todos os participantes.

Destaca-se também a diversidade de perspectivas teóricas envolvidas que permitiu aos discentes a ampliação dos conhecimentos até então adquiridos. Essas perspectivas, todas voltadas ao texto/discurso, contemplaram posições de pesquisas na linha Bakhtiniana, da Linguística de Texto (LT), da Teoria Semiolinguística do Discurso (TSD), da Análise Textual dos Discursos (ATD), da Linguística Cognitiva (LC), da Análise da Conversação (AC), das Teorias da Argumentação entre outras. Tratou-se de possibilitar aos discentes uma visão ampliada não só em termos epistemológicos, mas também holísticos que lhe permitissem olhares e caminhos do processo científico viáveis e profícuos na análise de textos/ discursos. Nesse sentido, foi possível identificar, durante as discussões das pesquisas, que os discentes se posicionavam com mais maturidade ao final do projeto interinstitucional, sendo mais críticos quanto a princípios teóricos, discernimento quanto a hipóteses e análise de resultados, por exemplo.

Nos vários encontros, foi possível conhecer o andamento das pesquisas, a partir de apresentações de trabalhos e debates que propiciaram imenso enriquecimento teórico e metodológico a todos. É importante destacar que as Universidades a que pertencem os integrantes das três equipes participantes (USP/UFRN/UNISINOS) disponibilizaram toda a infraestrutura e o apoio técnico necessários para o desenvolvimento das etapas do Projeto.

A participação de uma instituição federal (UFRN), uma estadual (USP) e uma privada (UNISINOS), pertencentes a regiões brasileiras distantes, permitiu que fossem vivenciadas realidades distintas que se coadunaram na pesquisa e no fortalecimento de laços acadêmicos, além de acrescentarem ampliação do universo cultural, traçando, no perfil dos alunos participantes, um desenho ímpar de cidadania, respeito e gratidão. A diminuição das assimetrias regionais foi o grande patamar alcançado, conforme dispunha o PROCAD em suas diretrizes. 


\section{Em torno do número 34/1 da revista Linha d'Água}

Os artigos selecionados para este número envolvem pesquisadores de vários estados brasileiros: Rio Grande do Norte, Ceará, Rio de Janeiro, Niterói, São Paulo, Rio Grande do Sul, mas também de pesquisadores de Portugal. Esses textos permitirão aos leitores compreender a interseção entre mídia e ensino.

O primeiro artigo de Maria das Graças Soares Rodrigues, intitula-se Ponto de vista emocionado no gênero discursivo comentário online: violência verbal analisa comentários produzidos por internautas online em um portal de notícias, em reação à matéria veiculada acerca de torturas sofridas por detentas em um presídio no Pará. Para tanto, a autora estabeleceu os seguintes objetivos: descrever, analisar e interpretar o ponto de vista (PDV) subjacente aos comentários dos locutores enunciadores primeiros (L1/E1) acerca de torturas sofridas por presidiárias. A análise revelou que os PDV subjacentes aos comentários se caracterizam pela violência verbal, tendo por efeito de sentido o sentimento de ódio. Os PDV são emocionados, decorrentes do aumento da tensão dos L1/E1, por ocasião da avaliação que fizeram acerca da situação. Certamente, o meio digital influenciou os L1/E1, no sentido de produzirem enunciados revestidos de ódio que não consideraram, em decorrência, a preservação de faces.

No artigo seguinte "No Impeachment de Dilma Rousseff: estratégias argumentativas em editoriais do jornal $O$ Globo", de Maria Eduarda Giering e Júlia Klein Caldas, focaliza-se uma pesquisa em que as autoras analisaram estratégias argumentativas utilizadas nos editoriais do jornal $O$ Globo, "Reformar a Previdência seria bom começo de Temer" e "Otimismo com o novo tom do Planalto", veiculados durante o processo de impeachment de Dilma Rousseff. Para tanto, objetivou-se identificar como os editoriais constroem os personagens envolvidos no processo e como a mídia pode influenciar a opinião pública. A metodologia considerou a situação de comunicação em que se inserem os editoriais, os procedimentos da construção enunciativa e os elementos de base da relação argumentativa. Como conclusão, identificaramse, nos editoriais analisados, o engajamento do locutor na defesa de uma tese favorável à destituição da então presidenta Dilma e a expressão da Opinião, que desqualifica o lulismo e o PT, por meio da modalidade delocutiva.

$\mathrm{O}$ artigo "A construção do sentido em interações verbais na rádio em Português Europeu: mecanismos discursivos em narrativas de experiência de vida", de Carla Aurélia de Almeida retoma um corpus de interações verbais realizadas na rádio em Portugal. O presente artigo analisa o modo como, nestes discursos, se estrutura o processo de construção do sentido. Para o efeito, considera o quadro enunciativo, as sequências de atos de discurso e as estratégias discursivas que permitem atribuir credibilidade e legitimidade ao discurso, captando a atenção. Analisam-se aspetos semânticos e pragmáticos da construção de narrativas de experiência de vida: as falas justapostas, as repetições, o uso da expressão aproximativa "e tal", o uso de "pronto" como marcador discursivo, a ocorrência de identidades na fala e a realização de asserções avaliativas. Neste contexto, consideram-se atos de autoelogio com mitigadores e com

\section{LINHA DÁGUA}


o recurso ao uso do verbo declarativo dizer na terceira pessoa do plural para minimizar a ameaça da face. Analisam-se ainda os comentários de avaliação que denotam a escuta atenta, permitindo fazer a gestão das trocas interacionais.

Beatriz dos Santos Feres, Patrícia Ferreira Neves Ribeiro e Rosane Santos Mauro Monnerat, no artigo intitulado "Rostos, afetos e intencionalidade: análise semiolinguística de marcas da pandemia", visam analisar textos verbo-visuais - uma matéria de capa de jornal e uma publicidade veiculada em revistas - que apresentam, em comum, rostos femininos marcados, em alguma medida, por indícios da pandemia de covid-19. Essa análise tem como objetivo destacar recursos discursivos que implicitam ideias, emoções e intencionalidades de acordo, sobretudo, com o imaginário sociodiscursivo partilhado pelos interagentes da troca propiciada por esses textos, no intuito de contribuir com um embasamento teórico-analítico para a elaboração de atividades de interpretação voltadas para a "Educação Midiática" proposta pela Base Nacional Comum Curricular. Tendo como fundamento a Teoria Semiolinguística de Análise do Discurso em interface com outros estudos, exploraram, inicialmente, os conceitos de imagem como signo, imagem-sintoma e intericonicidade. A seguir, tomando mais especificamente os textos em tela, foi observada a construção do ethos e da visada patêmica na discursivização.

Em Audiências de conciliação: determinações legais e interação, Marise Adriana Mamede Galvão e Anderson Souza da Silva Lanzillo propõem uma reflexão direcionada à interação em audiências de conciliação realizadas em um Fórum Cível no Estado do Rio Grande do Norte. Buscaram discutir algumas dimensões dessas audiências, guiados pelo que define a legislação (Código de Processo Civil e Lei dos Juizados Especiais), observando de que forma as regulações normativas influenciam os aspectos linguístico-discursivos. Nesse sentido, privilegiamos as evidências da organização geral da interação e as escolhas lexicais que permeiam as audiências, do ponto de vista da Conversação Institucional. Seguiram a orientação da Análise da Conversação para a construção do corpus de investigação, constituído por duas audiências de conciliação gravadas em vídeo e transcritas, conforme o sistema adotado pelos estudos de textos orais. A análise dos dados das audiências possibilitou reconhecer algumas regularidades na interação, marcadas pelo que é definido institucionalmente, haja vista o cumprimento de leis e orientações que se manifestam no plano linguístico-discursivo, a partir do léxico identificado nos dados da pesquisa.

Sandoval Nonato contribui para o número com o artigo intitulado Leitura, ensino de língua portuguesa e formação do professor. O artigo discute o estatuto da leitura como componente curricular da disciplina língua portuguesa na escola brasileira. Para tanto, apresenta, inicialmente, um panorama dos modos com que a leitura emerge no percurso histórico de constituição do ensino de língua portuguesa. Em seguida, contrasta esse estatuto historicamente construído com práticas de ensino de língua portuguesa atuais mediadas por estudantes de licenciatura em Letras, por ocasião de realização de estágio em escolas da rede pública da cidade de São Paulo (Brasil). A descrição e a análise do processo de implementação 
de um projeto de ensino destinado à leitura de contos da literatura marginal, por um estudante, conforme registrado em seu relatório de estágio, permitem problematizar alguns desafios que a prática de leitura em sala de aula coloca para o ensino e para a formação do professor de língua portuguesa.

Em Texto e construção de sentidos: propostas para leitura e interpretação, Maria Aparecida Lino Pauliukonis e Claudia Assad Alvares propõem a análise de inferências em textos, com o objetivo de demonstrar que todo sentido, mesmo o literal, inclui implícitos discursivos em diferentes graus. $\mathrm{O}$ ato de compreensão/interpretação desses enunciados envolve vários processos inferenciais, o que significa dizer que o leitor crítico deve estar atento não só às questões lógicas ou linguísticas stricto sensu, como também às discursivas e/ou retórico-argumentativas que ocorrem nos diversos gêneros de textos e que são fundamentais para a construção dos sentidos de uma produção textual. Um dos objetivos deste artigo consiste em apresentar propostas didático-pedagógicas para o ensino de leitura e de interpretação textual.

Sueli Cristina Marquesi e Andréa Pisan Soares Aguiar contribuem com o artigo $A$ revisão de texto por pares como metodologia ativa para o aprimoramento da escrita acadêmica. Neste artigo, as autoras têm como objetivo apresentar a aplicação da metodologia de aprendizagem por pares adaptada a uma atividade de revisão de texto acadêmico, especificamente de resumo de dissertação de mestrado. Para o desenvolvimento dessa proposta, buscaram o aporte teórico que trata de metodologias ativas, bem como de interação e de escrita como processo recursivo, do qual faz parte a etapa de revisão. As autoras entendem que abordar o ensino da escrita acadêmica da perspectiva de tais metodologias permite alinhá-lo ao paradigma, segundo o qual, o aluno assume um papel ativo na própria aprendizagem, e o professor torna-se um orientador de caminhos que possibilitam a construção individual e coletiva de conhecimentos.

O último artigo do número intitulado A proposta pedagógica de leitura de imagens em manuais de Língua Portuguesa do Ensino Médio é uma contribuição de Hylo Leal Pereira e Antônia Dilamar Araújo. Os autores propõem uma reflexão sobre o trabalho com imagens constante na subseção Leitura da imagem, presente na coleção Português: contexto, interlocução e sentido, obra integrante do PNLD de 2018, com o intuito de aproximar concepções teóricas atuais relacionadas aos multiletramentos e ao fazer pedagógico proposto para o professor de Língua Portuguesa no referido manual de ensino. Acrescentam-se a esse excurso teórico contribuições advindas da multimodalidade, do letramento visual e do letramento crítico. A pesquisa caracteriza-se por uma abordagem qualitativa e analisa duas das oito atividades presentes no terceiro volume da referida coleção. Conclui-se que há lacunas relativas ao trabalho com as teorias dos multiletramentos que, se preenchidas, tendem a potencializar as competências textuais relativas ao adequado letramento visual e crítico dos estudantes.

\section{LINHA DÁGUA}


Para o fechamento da edição, a resenha da obra Estudos sobre a argumentação no Brasil hoje: modelos teóricos e analíticos recurso eletrônico, organizado por Eduardo Lopes Piris e Maria das Graças Soares Rodrigues (Orgs.), foi redigido por Rosalice Pinto. Esse texto retoma aspectos importantes do compêndio como a pluralidade de perspectivas teóricas discutida pelos autores e a diversidade dos objetos de pesquisa.

No balanço desse editorial, precisamos destacar que os 10 textos de 17 autores foram produzidos na plataforma OJS no auge da pandemia provocada pela Covid-19. E o encerramento desse número foi marcado pela triste notícia da morte de colegas, funcionários e alunos da Universidade de São Paulo e de todas as universidades brasileiras e estrangeiras. Dois colegas do departamento de Letras Clássicas e Vernáculas da Faculdade de Filosofia, Letras e Ciências Humanas, Lineide do Lago Salvador Mosca e Alfredo Bosi, partiram no momento em que fechávamos esse número de Linha d'Água. Farão muita falta, partiram cedo demais, mas sempre habitarão nossa memória e nossos corações.

Convidamos todos os leitores a acessar os textos, navegando na diversas abordagens discursivas. Recebemos muitas submissões de artigos e mantivemos a seleção de textos porque contamos com competentes pareceristas do Conselho editorial e muitos professores ad hoc. Também contamos com a colaboração de um corpo de revisores de língua portuguesa de excelência, garantindo a alta qualidade da revisão de Linha d'Água. O trabalho de revisão de tradução de inglês é realizado pela professora Roseli Serra, da Universidade Católica de Pernambuco.

Neste ano de 2021, atravessamos uma fase difícil dos investimentos nas instituições de ensino superior com o congelamento de muitas verbas. Mesmo assim, Linha d'Água recebeu o auxílio do Programa de Apoio às Publicações Científicas Periódicas da Universidade de São Paulo, por meio da Agência USP de Gestão da Informação Acadêmica (Aguia), a quem agradecemos, mais uma vez, pelo inestimável e constante apoio e reconhecimento. Essas medidas têm permitido a manutenção da indexação de Linha d'Água na Web of Science, base de dados de citações científicas do Institute for Scientific Information, mantida pela Clarivate Analytics, nas áreas de Ciências Sociais, Artes e Humanidades e o trabalho do XML.

Com este número, Linha d'Água torna-se, assim, um espaço aberto a publicações ligadas aos estudos de língua portuguesa, aos estudos linguístico-discursivos e sua relação com o ensino, mantendo um diálogo constante com as pesquisas desenvolvidas no Brasil e no exterior.

\section{Referências}

ADAM, Jean-Michel. Postface. Le texte est-il soluble dans le textiel?. Corela - Cognition, représentation, langage, v. 18, n. 2, 2020a, p. 1-18. Disponível em: http://journals.openedition.org/corela/11938. Acesso em: 25 nov. 2020. DOI: https://doi.org/10.4000/corela.11938.

\section{LINHA DÁGUA}


ADAM, Jean-Michel. La notion de texte. In Encyclopédie Grammaticale du Français. Disponível em: http://encyclogram.fr. Acesso em: 12 out. 2019.

BAKHTIN, M. Teoria do romance I: a estilística. Trad. Paulo Bezerra. Org. edição russa Serguei Botcharov e Vadim Köjinov. São Paulo: 34, 2015, p. 41.

CHARAUDEAU, P. Compréhension et interprétation. Interrogations autour de deux modes d'appréhension du sens dans les sciences du langage. In: ACHARD-BAYLE, G.; GUÉRIN, M.; KLEIBER, G.; M. KRYLYCHIN (Dir.) Les sciences du langage et la question de l'interprétation (aujourd'hui). Paris: Les Éditions Lambert-Lucas, 2019.

CHARAUDEAU. P. Sobre o discurso científico e sua midiatização. Calidoscópio. Unisinos, v. 14, n. 3, p. 550-556, set/dez, 2016.

CHARAUDEAU, P. Um modelo sócio-comunicacional do discurso: entre situação de comunicação e estratégias de individualização. In: STAFUZZA, Grenissa; PAULA, Luciane de (org.) Da análise do discurso no Brasil à análise do discurso do Brasil, Edufu, Uberlândia, 2010. Disponível em: http://www.patrick-charaudeau.com/Um-modelo-socio-comunicacionaldo.html. Acesso em: 02 abr. 2021.

CHARAUDEAU, P. El contrato de comunicación en una perspectiva lingüística: Normas psicosociales y normas discursivas. Opcion, Maracaibo, v. 22, n. 49, p. 38-54, abr. 2006 a. Disponível em: http://ve.scielo.org/scielo.php?script=sci_arttext\&pid=S101215872006000100004\&lng=es\&nrm=iso. Acesso em: 02 abr. 2021.

CHARAUDEAU, P. Discurso das mídias. São Paulo: Contexto, $2006 \mathrm{~b}$.

CHARAUDEAU, P. Visadas discursivas, gêneros situacionais e construção textual. MACHADO, Ida Lúcia; MELLO, Renato de. (Orgs). Gêneros: reflexões em Análise do Discurso. Belo Horizonte: Núcleo de Análise do Discurso, UFMG, 2004.

CHARAUDEAU, P. Rôles sociaux et rôles langagiers. Modèles de l'interaction verbale, Aixen-Provence, Publications de 1'Université de Provence, 1995, p. 79-96.

São Paulo, abril de 2021. 
